\title{
Cognitive dysfunction and negative symptoms in patients with schizophrenia and their first-degree relatives from simplex and multiplex families
}

This article was published in the following Dove Press journal:

Neuropsychiatric Disease and Treatment

\section{Zhikun Zhang' \\ Rong Zhang ${ }^{2}$ \\ Peng Qin ${ }^{3}$ \\ Liwen $\operatorname{Tan}^{4}$}

'Mental Health Center, The Second Affiliated Hospital of Guangxi Medical University, Nanning, Guangxi, China; ${ }^{2}$ Department of Psychiatry, Staff Hospital of Zhongyuan Oil Field Company, Puyang, Henan, China; ${ }^{3}$ Department of Psychiatry, Changde Rehabilitation Hospital, Changde, Hunan, China; ${ }^{4}$ Department of Psychiatry, The Second Xiangya Hospital, Central South University, Changsha, Hunan, China
Correspondence: Liwen Tan Department of Psychiatry, The Second Xiangya Hospital, Central South University, No 139 Renmin Road, Changsha, Hunan 4100II, China

Tel +8673185292158

Email tanliwen@csu.edu.cn
Purpose: This study aimed to investigate cognitive functioning, negative symptoms, and the relationships in schizophrenia (SP) pedigrees and to explore the effect of genetic loading on those endophenotypes.

Patients and methods: Forty-four patients with SP, 81 first-degree non-psychotic relatives of patients from simplex and multiplex families, 14 matched control probands, and 29 first-degree relatives of the patients from communities were assessed by the vocabulary subtest (VS) of Wechsler Adult Intelligence Scale, memory span subtests of the Multiple Memory Assessment Scale (MMAS), Wisconsin Card Sorting Test (WCST), Continuous Performance Test (CPT), and Negative Scale of Positive and Negative Syndrome Scale.

Results: Compared with controls, patients with SP and their relatives had worse performances in WCST and CPT, and more serious negative symptoms. Patients from multiple families performed poorly on most tests while patients from simplex families had impairments only on the parameters of CPT and WSCT as compared to control probands. Patients from multiple families differed significantly from the patients from simplex families in the digit span and word span of MMAS. After controlling for education, in comparison with relatives of control probands, relatives from multiple families showed impairments in VS, multiple domains of CPT, whereas relatives from simplex families had lower scores on the VS and more total cards and random errors in WSCT. The performances of most tests were linked to negative symptoms in patients with SP. For patients with SP, VS, correct numbers and categories in the WCST, and visual and acoustic errors in the CPT predicted $68.8 \%$ of the variability in negative symptoms.

Conclusion: Our findings support that cognitive deficits and negative symptoms may be markers of hereditary susceptibility of SP and aggravate as the degree of genetic load increases. There are certain relationships between cognitive deficits and negative symptoms in patients with SP.

Keywords: schizophrenia, first-degree relatives, cognitive function, negative symptoms, genetic load

\section{Introduction}

Schizophrenia (SP) is a serious genetic mental illness with positive, negative, and cognitive symptoms. Negative symptoms and cognitive deficits can be found in the proband with SP, as well as in non-affected biological relatives, and thus may serve as makers of liability of SP. ${ }^{1}$

Cognitive symptoms in relatives of patients with SP have been the focus of studies in the past 20 years, and the deficits in executive domains, working memory, and sustained attention have been reported in them. There is substantial evidence that these neuropsychological impairments are suitable endophenotypes of SP. ${ }^{2-4}$ 
Negative symptoms are the pronounced characteristics of SP and also considered to be attractive intermediate phenotypes. 5,6 The measures of neuropsychological function, in conjunction with negative clinical symptoms, may provide a more accurate assessment of the liability produced by SP genes than currently available.

Because SP is a disease caused by multiple susceptibility genes, the severity of symptoms in patients and relatives may increase with the increase in genetic load for SP. ${ }^{7,8}$ Supporting this notion, several reports have shown that multiplex family members have greater impairment on the backward visual span, delayed story recall, disordered semantic verbal fluency, cognitive inhibition, and abnormal perceptual-motor speed than simplex family members. ${ }^{4,9}$ Birkett et $\mathrm{al}^{10}$ reported that there was no significant difference in the cognitive performance between SP patients with and without a family history of SP, but only between their non-psychotic relatives. Studies on the complex pedigrees are still limited.

As mentioned above, cognitive deficits and negative symptoms have been suggested to represent genetic markers of vulnerability to SP. Little is known about the relationship between two types of potential endophenotypes. Are cognitive deficits and negative symptoms the identical features of the illness with the same pathogenesis, or are cognitive deficits and negative symptoms two independent entities with separable genetic substrates ${ }^{11}$ ? Do these relationships exist in relatives of patients with SP?

In this study, cross-sectional design was employed to investigate the pedigree of SP. We hypothesized that there would be similar, although less pronounced, cognitive deficits and negative symptoms in first-degree relatives of SP patients, and cognitive deficits and negative symptoms in patients and relatives from multiplex families would be more severe than relatives from simplex families. Moreover, the relationships between cognitive deficits and negative symptoms in patients and their relatives are also discussed.

\section{Patients and methods}

\section{Participants}

A total of 165 subjects participated in this study, 44 of whom were patients with SP in and around Changsha city, 78 were first-degree non-psychotic relatives of patients with RP, 14 were normal control probands (CONP), and 29 were first-degree relatives (CONR) from communities in Changsha city. Specifically, 21 schizophrenic probands (SPS) and 52 relatives (RPS) were from 23 simplex families (one family member with SP). Twenty-three patients with SP (SPM) and 26 relatives (RPM) were from 13 multiplex families (at least two family members with SP). Subjects with an estimated intelligence quotient (IQ) $<70$, a history of a neurological disease, a physical disease with central nervous system impairment, head injury with documented loss of consciousness exceeding 5 minutes, electroconvulsive treatment, or alcohol/substance abuse within prior 6 months were excluded from this study. In addition, normal controls did not have a first- or second-degree biological relative with SP or a related disorder of SP spectrum. Five patients were excluded from the study because they did not complete the cognitive tests.

Patients with SP were diagnosed according to the structured clinical interview for $D S M-I V$. All patients received anti-psychotic treatments, including clozapine, risperidone, olanzapine, or sulpiride, and were in a stable stage without positive symptoms. The Institutional Review Board of the Second Xiangya Hospital approved this study, and all the participants gave written informed consent.

\section{Neuropsychological measures}

All participants were evaluated with a set of neuropsychological tests to assess the cognitive function. All participants received assessments with the Wisconsin Card Sorting Test (WCST), ${ }^{12}$ Continuous Performance Test (CPT), ${ }^{13}$ vocabulary subtest (VS) from Wechsler Adult Intelligence Scale (WAIS-R), and memory span from Multiple Memory Assessment Scale (MMAS). ${ }^{14}$

\section{WCST}

WCST is a multiplex measurement of executive function, in which mental flexibility, working memory, and goal-directed behaviors are assessed. Following parameters of WCST are measured: total cards, correct numbers, perseverative errors, random errors, and correct categories numbers. ${ }^{12}$

\section{CPT}

CPT is a test of measuring sustained attention, early visual information processing, and response inhibition. Six parameters are examined: visual errors, visual omission, visual reaction time, acoustic errors, acoustic omission, and acoustic reaction time. ${ }^{13}$

\section{VS}

VS was used to measure the ability of generalizing abstraction and verbalization. Total score is recorded according to the manual of WAIS-R, Chinese version. ${ }^{15}$

\section{MMAS}

MMAS is designed by Cheng et a ${ }^{14}$ with satisfied reliability and validity. Memory span is a measure of working memory. 
It has three parts: digit span, word span, and spatial span. Total correct numbers of every part are recorded. ${ }^{14}$

\section{Negative symptoms}

Negative symptoms were estimated by the Negative Scale of Positive and Negative Syndrome Scale (PANSS). The severity of each symptom was scored with one of seven grades $(1=$ absent, $2=$ minimal, $3=$ mild, $4=$ moderate, $5=$ moderate severe, $6=$ severe, and $7=$ extreme). ${ }^{16}$

\section{Statistical analysis}

Group differences were analyzed using one-way ANOVA for group comparisons for continuous variables, and chisquared tests for categorical variables. Considering there were significant differences in age among SPM, SP, and CONP groups, age was used as a covariate when these three groups were analyzed. Likewise, education was included as a covariate in comparisons among RPM, RPS, and CONR groups. Follow-up post hoc tests (least square differences) were used to assess group differences when overall effects were significant.

The Spearman correlational analyses were performed by focusing on the associations between the scores of neuropsychological measures and negative symptoms. Stepwise multiple linear regressions were then performed based on age, education, and all the scores of neuropsychological measures to determine the role of these variables in explaining the negative symptoms. Logarithmic values of negative symptoms were considered dependent variables. A value of $P<0.05$ was considered statistically significant.

\section{Results}

\section{Demographic characteristics of subjects}

Demographics are presented in Table 1. There were no significant differences in the age, gender, and education between $\mathrm{SP}$ and CONP. The demographics were also comparable between RP and CONR. However, after the SP or RP were divided into two groups according to their families, there was significant difference in the age among SPM, SPS, and CONP groups $(F=4.091 ; d f=2,54 ; P=0.022)$, and marked difference in the education among RPM, RPS, and CONR groups $(F=4.667 ; d f=2,54 ; P=0.011)$, while other demographics were comparable across groups.

\section{Endophenotypes}

\section{Cognitive function}

Compared with CONP, SP had fewer correct numbers and correct categories in the WCST, and poor performance on all parameters in the CPT (Table 2). The RP had lower scores on the VS, fewer correct numbers and correct categories in the WCST, and more visual omission and reaction times in the CPT when compared with CONR (Table 3).

In addition, there was a significant difference among SPM, SPS, and CONP groups on certain parts of neuropsychological tests (Table 4). Age was included as a covariate in comparisons among the three groups. All reported $P$-values were subjected to Bonferroni correction for multiple testing. Significant group differences were found in the following parameters: VS: $F=3.2 ; d f=2,53 ; P=0.047$; digit span of MMAS: $F=3.7 ; d f=2,53 ; P=0.044$; word span of MMAS: $F=7.5 ; d f=2,53 ; P=0.001$; total cards of WSCT: $F=4.0 ; d f=2,53 ; P=0.023$; random errors of WSCT: $F=3.6$; $d f=2,53 ; P=0.035$; visual omission of CPT: $F=6.3 ; d f=2$, 53; $P=0.004$; visual reaction time of CPT: $F=4.5 ; d f=2,53$; $P=0.016$; acoustic errors of CPT: $F=3.1 ; d f=2,53 ; P=0.005$; acoustic omission of CPT: $F=4.9 ; d f=2,53 ; P=0.011$; acoustic reaction time of CPT: $F=3.3 ; d f=2,53 ; P=0.044$. In post hoc comparisons, the SPM performed poorly on most tests while the SPS had impairments only on the parameters of CPT and WSCT as compared to CONP. The SPM differed significantly from the SPS in the digit span and word span of MMAS. Significant difference in the cognitive functioning was also observed across RPM, RPS, and CONR groups (Table 5). All reported $P$-values were subjected to Bonferroni

Table I Demographics of subjects included in this study

\begin{tabular}{|c|c|c|c|c|c|c|}
\hline $\begin{array}{l}\text { Demographic } \\
\text { parameter }\end{array}$ & $\begin{array}{l}\text { SPM } \\
(n=23)\end{array}$ & $\begin{array}{l}\text { SPS } \\
(n=2 I)\end{array}$ & $\begin{array}{l}\text { CONP } \\
(n=14)\end{array}$ & $\begin{array}{l}\text { RPM } \\
(n=26)\end{array}$ & $\begin{array}{l}\text { RPS } \\
(n=52)\end{array}$ & $\begin{array}{l}\text { CONR } \\
(n=29)\end{array}$ \\
\hline $\begin{array}{l}\text { Age (year) } \\
\text { Mean (SD) }\end{array}$ & $29.8(9.8)^{*}$ & $22.5(7.6)$ & $22.9(10.9)$ & $45.3(13.8)$ & $38.9(14.1)$ & $39.8(13.0)$ \\
\hline $\begin{array}{l}\text { Education years } \\
\text { Mean (SD) }\end{array}$ & $10.0(2.9)$ & $10.8(2.4)$ & $10.6(2.8)$ & $7.7(3.7)^{* *}$ & $10.0(3.4)$ & $9.8(2.6)$ \\
\hline Male:female & $9: 14$ & $7: 14$ & $7: 7$ & $13: 13$ & $22: 30$ & $13: 16$ \\
\hline $\begin{array}{l}\text { Duration, years } \\
\text { Mean (SD) }\end{array}$ & $6.9(5.2)$ & $4.5(3.7)$ & - & - & - & - \\
\hline
\end{tabular}

Note: *The average age of SPM groups is higher than the age of SPS and CONP groups. $(P=0.012, P=0.033)$. **The average education years of RPM groups is less than that of RPS and CONR groups. $(P=0.004, P=0.015)$.

Abbreviations: SPM, patients from multiplex families; SPS, patients from simplex families; CONP, control proband; RPM, relative of patients from multiplex families; RPS, relative of patients from simplex families; CONR, relative of control proband. 
Table 2 Results of cognitive testing and negative symptom assessment in probands of patients with schizophrenia and controls

\begin{tabular}{|c|c|c|c|c|c|c|}
\hline \multirow{2}{*}{$\begin{array}{l}\text { Neuropsychological } \\
\text { measures \& negative } \\
\text { symptoms }\end{array}$} & \multicolumn{2}{|c|}{ SP $(n=44)$} & \multicolumn{2}{|c|}{ CONP $(n=14)$} & \multirow[t]{2}{*}{$F(d f=I)$} & \multirow[t]{2}{*}{$P$-value } \\
\hline & $M$ & SD & $M$ & SD & & \\
\hline \multicolumn{7}{|l|}{ Abstraction } \\
\hline VS & 49.6 & 20.9 & 60.6 & 12.8 & 3.107 & 0.083 \\
\hline \multicolumn{7}{|c|}{ Short-time working memory } \\
\hline \multicolumn{7}{|c|}{ MS } \\
\hline Digit span & 10.6 & 3.0 & 11.4 & 2.8 & 0.103 & 0.749 \\
\hline Word span & 7.5 & 2.2 & 8.8 & 2.5 & 0.010 & 0.920 \\
\hline Spatial span & 6.3 & 2.1 & 7.3 & 2.6 & 1.208 & 0.276 \\
\hline \multicolumn{7}{|l|}{ Executive function } \\
\hline \multicolumn{7}{|l|}{ WCST } \\
\hline Total cards & 84.5 & 28.0 & 64.0 & 21.3 & 1.670 & 0.202 \\
\hline Correct numbers & 23.2 & 5.3 & 25.0 & 0.0 & 6.588 & 0.013 \\
\hline Perseverative errors & 22.5 & 12.1 & 18.3 & 8.4 & 1.632 & 0.207 \\
\hline Random errors & 38.8 & 25.7 & 20.7 & 14.9 & 3.155 & $0.08 I$ \\
\hline Correct categories & 4.6 & 1.1 & 5.0 & 0.0 & 7.884 & 0.007 \\
\hline \multicolumn{7}{|l|}{ Continuous attention } \\
\hline \multicolumn{7}{|l|}{ CPT } \\
\hline Visual errors & 55.1 & 14.4 & 47.8 & 5.7 & 6.826 & 0.012 \\
\hline Visual omission & 67.8 & 18.0 & 49.0 & 3.4 & 64.987 & 0.000 \\
\hline Visual reaction time & 58.6 & 15.3 & 46.5 & 5.9 & 8.679 & 0.005 \\
\hline Acoustic errors & 61.0 & 16.4 & 48.5 & 5.3 & $|4.07|$ & 0.000 \\
\hline Acoustic omission & 69.9 & 19.0 & 53.5 & 10.9 & 20.959 & 0.000 \\
\hline Acoustic reaction time & 54.9 & 14.1 & 45.8 & 6.5 & 5.892 & 0.018 \\
\hline \multicolumn{7}{|l|}{ Negative symptoms } \\
\hline NI & 2.8 & 1.2 & 1.2 & 0.4 & 15.399 & 0.000 \\
\hline N2 & 2.5 & 1.4 & 1.1 & 0.3 & 30.442 & 0.000 \\
\hline N3 & 2.3 & 1.0 & 1.1 & 0.5 & 12.860 & 0.001 \\
\hline $\mathrm{N} 4$ & 2.6 & 1.3 & 1.1 & 0.3 & 21.954 & 0.000 \\
\hline N5 & 3.2 & 1.8 & 1.6 & 0.9 & 7.510 & 0.008 \\
\hline N6 & 2.4 & 1.5 & 1.0 & 0.0 & 34.502 & 0.000 \\
\hline N7 & 1.8 & 1.1 & 1.1 & 0.5 & 9.165 & 0.004 \\
\hline Total & 17.2 & 7.3 & 8.3 & 0.7 & 26.435 & 0.000 \\
\hline
\end{tabular}

Note: $d f=I$.

Abbreviations: VS, vocabulary subtest from Wechsler Adult Intelligence Scale; MS, memory span from Multiple Memory Assessment Scale; WCST, Wisconsin Card Sorting Test; CPT, Continuous Performance Test; SP, patients with schizophrenia; CONP, control proband; M, mean.

correction for multiple testing. Significant group differences were found in the following parameters: VS: $F=6.0 ; d f=2$, 103; $P=0.003$; digit span of MMAS: $F=3.3 ; d f=2,103$; $P=0.039$; total cards of WSCT: $F=3.1 ; d f=2,103 ; P=0.048$; random errors of WSCT: $F=3.1 ; d f=2,103 ; P=0.045$; visual errors of CPT: $F=3.2 ; d f=2,103 ; P=0.041$; visual omission of CPT: $F=7.2 ; d f=2,103 ; P=0.001$; acoustic errors of CPT: $F=4.5 ; d f=2,103 ; P=0.013$; acoustic omission of CPT: $F=3.5$; $d f=2,103 ; P=0.034$; acoustic reaction time of CPT: $F=3.0$; $d f=2,103 ; P=0.005$. After controlling for education, in comparison with CONR group, RPM group showed impairments in VS, multiple domains of CPT, whereas RPS group had lower scores on the VS and more total cards and random errors in WSCT. As compared to RPS, RPM group had worse performances in digit span of MMAS and multiple domains of CPT.

\section{Negative symptoms}

The scores for negative symptoms in SP and RP were significantly higher than in CONP and CONR across all items. In addition, SPM and SPS groups scored higher than CONP in analysis of variance, but significant difference was not observed between SPM and SPS groups. Analysis of variance indicated that RPM group had higher scores in all subscale items than CONR group, and in items N1, N2, $\mathrm{N} 3$, and $\mathrm{N} 7$ and total scores of negative symptoms than RPS group. Compared with CONR, RPS showed more score in item N5 (Tables 4 and 5).

\section{Spearman correlation analysis and stepwise regression analysis}

The performance of VS, word span and spatial span in MMAS, total cards, correct numbers, random errors, correct 
Table 3 Results of cognitive testing and negative symptom assessment in relatives of patients with schizophrenia and controls

\begin{tabular}{|c|c|c|c|c|c|c|}
\hline \multirow{2}{*}{$\begin{array}{l}\text { Neuropsychological measures } \\
\text { \& negative symptoms }\end{array}$} & \multicolumn{2}{|c|}{$\operatorname{RP}(n=78)$} & \multicolumn{2}{|c|}{ CONR $(n=29)$} & \multirow[t]{2}{*}{$F(d f=I)$} & \multirow[t]{2}{*}{$P$-value } \\
\hline & $M$ & SD & $M$ & SD & & \\
\hline \multicolumn{7}{|l|}{ Abstraction } \\
\hline VS & 49.9 & 18.6 & 62.6 & 11.2 & 5.136 & 0.025 \\
\hline \multicolumn{7}{|l|}{ Short-time working memory } \\
\hline \multicolumn{7}{|l|}{ MS } \\
\hline Digit span & 10.2 & 2.5 & 10.6 & 2.1 & 0.373 & 0.543 \\
\hline Word span & 7.3 & 1.4 & 7.7 & 1.6 & 0.004 & 0.950 \\
\hline Spatial span & 6.4 & 2.1 & 6.2 & 1.4 & 2.912 & 0.091 \\
\hline \multicolumn{7}{|l|}{ Executive function } \\
\hline \multicolumn{7}{|l|}{ WCST } \\
\hline Total cards & 81.9 & 28.4 & 68.9 & 23.2 & 2.674 & 0.105 \\
\hline Correct numbers & 24.2 & 3.3 & 25.0 & 0.0 & 6.287 & $0.014 *$ \\
\hline Perseverative errors & 22.9 & 12.6 & 18.3 & 8.7 & 2.008 & 0.159 \\
\hline Random errors & 35.3 & 22.7 & 25.8 & 18.0 & 2.605 & 0.110 \\
\hline Correct categories & 4.8 & 0.8 & 5.0 & 0.0 & 8.325 & $0.005^{*}$ \\
\hline \multicolumn{7}{|l|}{ Continuous attention } \\
\hline \multicolumn{7}{|l|}{ CPT } \\
\hline Visual errors & 49.6 & 7.0 & 50.2 & 9.7 & 0.585 & 0.446 \\
\hline Visual omission & 58.0 & 14.7 & $5 \mathrm{I} . \mathrm{I}$ & 8.4 & 15.156 & $0.000 *$ \\
\hline Visual reaction time & 49.9 & 9.2 & 47.0 & 6.2 & 4.126 & $0.045^{*}$ \\
\hline Acoustic errors & 50.5 & 9.1 & 50.1 & 5.7 & 2.301 & 0.132 \\
\hline Acoustic omission & 61.5 & 16.8 & 56.9 & 15.8 & 0.918 & 0.340 \\
\hline Acoustic reaction time & 48.8 & 9.7 & 44.8 & 9.4 & 0.012 & 0.914 \\
\hline \multicolumn{7}{|l|}{ Negative symptoms } \\
\hline $\mathrm{NI}$ & 1.4 & 0.7 & 1.2 & 0.4 & 16.608 & $0.000 *$ \\
\hline N2 & 1.3 & 0.7 & 1.1 & 0.3 & 14.849 & $0.000 *$ \\
\hline N3 & 1.5 & 0.7 & 1.2 & 0.4 & 11.127 & $0.001 *$ \\
\hline N4 & 1.3 & 0.6 & 1.0 & 0.2 & 23.534 & $0.000 *$ \\
\hline N5 & 2.7 & 1.4 & 2.0 & 0.9 & 4.756 & $0.03 I^{*}$ \\
\hline N6 & 1.4 & 0.8 & 1.0 & 0.2 & 28.667 & $0.000 *$ \\
\hline N7 & 1.2 & 0.6 & 1.1 & 0.4 & 4.229 & $0.042 *$ \\
\hline Total & 10.9 & 3.8 & 8.7 & 1.8 & 9.097 & $0.003 *$ \\
\hline
\end{tabular}

Notes: $d f=1 . * P<0.05$ between RP and CONR group.

Abbreviations: VS, vocabulary subtest from Wechsler Adult Intelligence Scale; MS, memory span from Multiple Memory Assessment Scale; WCST, Wisconsin Card Sorting Test; CPT, Continuous Performance Test; RP, relatives of patients; CONR, relatives of control proband.

categories in WCST, visual errors, visual reaction time, acoustic errors, acoustic omission, and reaction times in CPT correlated significantly with negative symptoms in patients with SP (Table 6). The performance of VS, digit span, word span, and spatial span in MMAS, and visual omission and visual reaction times in CPT correlated significantly with negative symptoms in relatives of patients with SP (Table 7).

All the scores of neuropsychological tests, together with age and education, were included as predictors in stepwise regression model and the logarithmic values of negative symptoms as the dependent variable. As detailed in Table 8 , for the patients, the final regression model accounted for $68.8 \%$ of negative symptom variance. The results of stepwise regression analysis of VS (step 1), correct categories (step 2), acoustic errors (step 3), correct numbers (step 4), and visual errors (step 5) are presented in Table 8. For the relatives of patients, the final regression model accounted for $63.9 \%$ of negative symptom variance. The results of stepwise regression of VS (step 1) and visual omission in CPT (step 2) are presented in Table 9.

\section{Discussion}

In this study, an endophenotypic strategy was employed to evaluate the effect of genetic load of SP. Our results showed that probands with SP showed deficits across a range of cognitive domains and the unaffected first-degree relatives were also impaired in specific domains compared with healthy subjects without a family history. Patients with SP had the most pronounced negative symptoms, while relatives of patients showed an intermediate impairment between patients and CONP. As expected, an increased genetic risk was accompanied by increased impairments in these domains. These findings support the potential of neurocognitive measures 
Table 4 Results of cognitive testing and negative symptom assessment in patients with schizophrenia from simplex families and multiplex families and controls

\begin{tabular}{|c|c|c|c|c|c|c|c|c|c|}
\hline \multirow{2}{*}{$\begin{array}{l}\text { Neuropsychological measures } \\
\text { \& negative symptoms }\end{array}$} & \multicolumn{2}{|c|}{ SPM $(n=23)$} & \multicolumn{2}{|c|}{ SPS $(n=2 I)$} & \multicolumn{2}{|c|}{ CONP $(n=14)$} & \multirow{2}{*}{$\begin{array}{l}\text { SPM vs } \\
\text { CONP } \\
\text { PI }\end{array}$} & \multirow{2}{*}{\begin{tabular}{|l|} 
SPS vs \\
CONP \\
P2 \\
\end{tabular}} & \multirow{2}{*}{$\begin{array}{l}\text { SPM vs } \\
\text { SPS } \\
\text { P3 }\end{array}$} \\
\hline & Mean & SD & Mean & SD & Mean & SD & & & \\
\hline \multicolumn{10}{|l|}{ Abstraction } \\
\hline VS & 45.8 & 4.2 & 53.8 & 4.3 & 60.4 & 5.2 & 0.042 & $>0.05$ & $>0.05$ \\
\hline \multicolumn{10}{|l|}{ Short-time working memory } \\
\hline \multicolumn{10}{|l|}{ MS } \\
\hline Digit span & 9.7 & 0.6 & 11.8 & 0.6 & 11.2 & 0.7 & $>0.05$ & $>0.05$ & 0.049 \\
\hline Word span & 6.5 & 0.5 & 8.6 & 0.5 & 8.8 & 0.6 & 0.001 & $>0.05$ & 0.006 \\
\hline Spatial span & 6.2 & 0.5 & 6.5 & 0.5 & 7.2 & 0.6 & $>0.05$ & $>0.05$ & $>0.05$ \\
\hline \multicolumn{10}{|l|}{ Executive function } \\
\hline \multicolumn{10}{|l|}{ WCST } \\
\hline Total cards & 86.7 & 5.7 & 81.4 & 5.9 & 65.2 & 7.1 & 0.007 & 0.041 & $>0.05$ \\
\hline Correct numbers & 23.5 & 1.0 & 23.2 & 1.0 & 24.5 & 1.2 & $>0.05$ & $>0.05$ & $>0.05$ \\
\hline Perseverative errors & 23.7 & 2.5 & 21.1 & 2.5 & 18.5 & 3.1 & $>0.05$ & $>0.05$ & $>0.05$ \\
\hline Random errors & 39.5 & 5.1 & 37.1 & 5.2 & 22.2 & 6.3 & 0.013 & 0.035 & $>0.05$ \\
\hline Correct categories & 4.7 & 0.2 & 4.6 & 0.2 & 4.9 & 0.2 & $>0.05$ & $>0.05$ & $>0.05$ \\
\hline \multicolumn{10}{|l|}{ Continuous attention } \\
\hline \multicolumn{10}{|l|}{ CPT } \\
\hline Visual errors & 58.6 & 2.8 & 51.5 & 2.8 & 48.4 & 3.5 & $>0.05$ & $>0.05$ & $>0.05$ \\
\hline Visual omission & 65.9 & 3.5 & 69.5 & 3.6 & 49.6 & 4.3 & 0.013 & 0.001 & $>0.05$ \\
\hline Visual reaction time & 56.5 & 3.0 & 60.6 & 3.1 & 47.0 & 3.7 & $>0.05$ & 0.004 & $>0.05$ \\
\hline Acoustic errors & 63.8 & 3.2 & 58.4 & 3.3 & 50.1 & 5.7 & 0.016 & $>0.05$ & $>0.05$ \\
\hline Acoustic omission & 69.3 & 3.9 & 70.6 & 3.9 & 53.6 & 4.8 & 0.021 & 0.003 & $>0.05$ \\
\hline Acoustic reaction time & 57.0 & 2.8 & 52.7 & 2.9 & 45.8 & 3.5 & 0.039 & $>0.05$ & $>0.05$ \\
\hline \multicolumn{10}{|l|}{ Negative symptoms } \\
\hline $\mathrm{NI}$ & 2.8 & 0.2 & 2.8 & 0.2 & 1.2 & 0.3 & 0.003 & 0.002 & $>0.05$ \\
\hline N2 & 2.6 & 0.3 & 2.4 & 0.3 & I.I & 0.3 & 0.008 & 0.009 & $>0.05$ \\
\hline N3 & 2.3 & 0.2 & 2.4 & 0.2 & I.I & 0.2 & 0.007 & 0.005 & $>0.05$ \\
\hline N4 & 2.6 & 0.3 & 2.6 & 0.3 & I.I & 0.3 & 0.002 & 0.002 & $>0.05$ \\
\hline N5 & 3.4 & 0.3 & 2.9 & 0.4 & 1.7 & 0.4 & 0.012 & $>0.05$ & $>0.05$ \\
\hline N6 & 2.4 & 0.3 & 2.4 & 0.3 & 1.0 & 0.4 & 0.008 & 0.006 & $>0.05$ \\
\hline N7 & 1.9 & 0.2 & 1.8 & 0.2 & 1.2 & 0.3 & $>0.05$ & $>0.05$ & $>0.05$ \\
\hline Total & 17.5 & 1.9 & 16.7 & 1.6 & 9.3 & 1.9 & 0.003 & 0.003 & $>0.05$ \\
\hline
\end{tabular}

Notes: PI: SPM vs CONP, P2: SPS vs CONP, P3: SPM vs SPS. Bold values represent $P<0.05$.

Abbreviations: VS, vocabulary subtest from Wechsler Adult Intelligence Scale; MS, memory span from Multiple Memory Assessment Scale; WCST, Wisconsin Card Sorting Test; CPT, Continuous Performance Test; SPM, patients from multiplex families; SPS, patients from simplex families; CONP, control proband.

and negative symptoms as endophenotypic markers of vulnerability to SP. ${ }^{6,17}$

After subdividing the patients and their relatives from multiplex or simplex families, the results showed that both patients and relatives from multiplex families performed significantly worse in measures of vocabulary explanation, visual omission, acoustic errors, acoustic omission, and acoustic reaction time in CPT than controls. The cognitive impairment in relatives from simplex families was relatively mild. Genetic load affected the performance of cognitive function; the higher the genetic load, the more serious the cognitive deficits were. Genetic load was also consistent with the previous hypothesis that SP is a polygenetic disease. Because the exact genes associated with SP have not been identified, grouping the population based on genetic load may be an effective strategy to improve the power in similar research studies.

Snitz et al ${ }^{18}$ found that $75 \%$ of relatives performed more poorly than controls in working memory demands set shifting and inhibition of pre-potent responses. In the present study, there was no significant difference in the working memory between relatives of patients and controls. Several reasons should be considered. First, the short-time memory is more easily influenced by mental status, environment, or other factors than cognitive function. Second, memory span may be a basic component of working memory, and it is difficult to detect the slight difference between relatives of patients and normal controls by the memory span tests. More challenging tasks would be suggested to acquire meaningful results. ${ }^{3}$ 
Table 5 Results of cognitive testing and negative symptom assessment in relatives of patients with schizophrenia from simplex families and multiplex families and controls

\begin{tabular}{|c|c|c|c|c|c|c|c|c|c|}
\hline \multirow{2}{*}{$\begin{array}{l}\text { Neuropsychological measures } \\
\text { \& negative symptoms }\end{array}$} & \multicolumn{2}{|c|}{$\operatorname{RPM}(n=26)$} & \multicolumn{2}{|c|}{$\operatorname{RPS}(n=52)$} & \multicolumn{2}{|c|}{ CONR $(n=29)$} & \multirow{2}{*}{$\begin{array}{l}\text { RPM vs } \\
\text { CONR } \\
\text { P4 }\end{array}$} & \multirow{2}{*}{\begin{tabular}{|l} 
RPS vs \\
CONR \\
P5 \\
\end{tabular}} & \multirow{2}{*}{$\begin{array}{l}\text { RPM vs } \\
\text { RPS } \\
\text { P6 } \\
\end{array}$} \\
\hline & Mean & SD & Mean & SD & Mean & SD & & & \\
\hline \multicolumn{10}{|l|}{ Abstraction } \\
\hline VS & 48.9 & 2.6 & 51.3 & 1.8 & 60.9 & 2.3 & 0.005 & 0.002 & $>0.05$ \\
\hline \multicolumn{10}{|l|}{ Short-time working memory } \\
\hline MS & & & & & & & & & \\
\hline Digit span & 9.6 & 0.4 & 10.6 & 0.3 & 10.4 & 0.3 & $>0.05$ & $>0.05$ & 0.026 \\
\hline Word span & 7.1 & 0.2 & 7.5 & 0.2 & 7.6 & 0.2 & $>0.05$ & $>0.05$ & $>0.05$ \\
\hline Spatial span & 6.2 & 0.4 & 6.6 & 0.3 & 6.1 & 0.3 & $>0.05$ & $>0.05$ & $>0.05$ \\
\hline \multicolumn{10}{|l|}{ Executive function } \\
\hline \multicolumn{10}{|l|}{ WCST } \\
\hline Total cards & 78.9 & 5.0 & 82.4 & 3.4 & 70.6 & 4.6 & $>0.05$ & 0.019 & $>0.05$ \\
\hline Correct numbers & 23.9 & 0.5 & 24.2 & 0.4 & 24.9 & 0.5 & $>0.05$ & $>0.05$ & $>0.05$ \\
\hline Perseverative errors & 23.7 & 2.2 & 22.2 & 1.5 & 20.0 & 2.0 & $>0.05$ & $>0.05$ & $>0.05$ \\
\hline Random errors & 33.2 & 4.1 & 35.7 & 2.8 & 27.0 & 3.8 & $>0.05$ & 0.044 & $>0.05$ \\
\hline Correct categories & 4.7 & 0.1 & 4.9 & 0.1 & 5.0 & 0.1 & $>0.05$ & $>0.05$ & $>0.05$ \\
\hline \multicolumn{10}{|l|}{ Continuous attention } \\
\hline \multicolumn{10}{|l|}{ CPT } \\
\hline Visual errors & 52.1 & 1.6 & 48.3 & 1.1 & 50.2 & $\mathrm{I} .4$ & $>0.05$ & $>0.05$ & 0.027 \\
\hline Visual omission & 63.5 & 2.5 & 55.1 & 1.7 & 51.5 & 2.3 & 0.000 & $>0.05$ & 0.004 \\
\hline Visual reaction time & 52.3 & 1.6 & 48.5 & 1.1 & 47.4 & 1.5 & $>0.05$ & $>0.05$ & $>0.05$ \\
\hline Acoustic errors & 54.3 & 1.6 & 48.8 & 1.3 & 50.0 & 1.5 & 0.024 & $>0.05$ & 0.003 \\
\hline Acoustic omission & 67.2 & 3.3 & 58.5 & 2.2 & 57.2 & 3.0 & 0.015 & $>0.05$ & 0.019 \\
\hline Acoustic reaction time & 51.2 & 1.9 & 47.6 & 1.3 & 44.8 & 1.8 & 0.050 & $>0.05$ & $>0.05$ \\
\hline \multicolumn{10}{|l|}{ Negative symptoms } \\
\hline $\mathrm{NI}$ & 1.7 & 0.1 & 1.3 & 0.1 & 1.2 & 0.2 & 0.018 & $>0.05$ & 0.047 \\
\hline N2 & 1.7 & 0.1 & 1.2 & 0.1 & I.I & 0.1 & 0.003 & $>0.05$ & 0.003 \\
\hline N3 & 1.8 & 0.1 & 1.3 & 0.1 & 1.2 & 0.1 & 0.016 & $>0.05$ & 0.015 \\
\hline N4 & 1.5 & 0.1 & 1.2 & 0.1 & 1.0 & 0.1 & 0.028 & $>0.05$ & $>0.05$ \\
\hline N5 & 3.0 & 0.2 & 2.6 & 0.2 & 2.0 & 0.2 & 0.048 & 0.017 & $>0.05$ \\
\hline N6 & 1.6 & 0.1 & 1.3 & 0.1 & 1.0 & 0.1 & 0.049 & $>0.05$ & $>0.05$ \\
\hline N7 & 1.5 & 0.1 & 1.0 & 0.1 & I.I & 0.1 & 0.035 & $>0.05$ & 0.015 \\
\hline Total & 12.0 & 0.6 & 10.2 & 0.4 & 9.2 & 0.5 & 0.001 & $>0.05$ & 0.014 \\
\hline
\end{tabular}

Notes: P4: RPM vs CONR, P5: RPS vs CONR, P6: RPM vs RPS. Education was included as a covariate in comparisons among the three groups. Follow-up post hoc test (least square differences) was used for the comparisons when overall effects were significant. A value of $P<0.05$ was considered statistically significant. Bold values represent $P<0.05$.

Abbreviations: VS, vocabulary subtest from Wechsler Adult Intelligence Scale; MS, memory span from Multiple Memory Assessment Scale; WCST, Wisconsin Card Sorting Test; CPT, Continuous Performance Test; RPM, relative of patients from multiplex families; RPS, relative of patients from simplex families; CONR, relatives of control proband.

The VS tests the ability of generalizing abstraction and verbalization. Among the relatives of the three groups, the relatives of patients with SP from simplex families and multiplex families had the evident impairment in the VS.
There was a similar trend among the patients with SP from simplex families and multiplex families and controls, though the difference between patients from simplex families and controls failed to show significance. The VS is usually used

Table 6 Spearman correlational analysis between negative symptoms and scores of neuropsychological measures in patients with schizophrenia

\begin{tabular}{|l|l|l|l|l|l|l|l|l|l|}
\hline & VS & $\begin{array}{l}\text { Digit } \\
\text { span }\end{array}$ & $\begin{array}{l}\text { Word } \\
\text { span }\end{array}$ & $\begin{array}{l}\text { Spatial } \\
\text { span }\end{array}$ & $\begin{array}{l}\text { Total } \\
\text { cards }\end{array}$ & $\begin{array}{l}\text { Correct } \\
\text { numbers }\end{array}$ & $\begin{array}{l}\text { Perseverative } \\
\text { errors }\end{array}$ & $\begin{array}{l}\text { Random } \\
\text { errors }\end{array}$ & $\begin{array}{l}\text { Correct } \\
\text { categories }\end{array}$ \\
\hline $\mathrm{r}$ & $-0.713^{* *}$ & -0.257 & $-0.548^{* *}$ & $-0.419 * *$ & $0.464^{* *}$ & $-0.394^{* *}$ & 0.261 & $0.463^{* *}$ & $-0.394^{* *}$ \\
\hline $\begin{array}{l}\text { Visual } \\
\text { errors }\end{array}$ & $\begin{array}{l}\text { Visual } \\
\text { omission }\end{array}$ & $\begin{array}{l}\text { Visual } \\
\text { reaction } \\
\text { time }\end{array}$ & $\begin{array}{l}\text { Acoustic } \\
\text { errors }\end{array}$ & $\begin{array}{l}\text { Acoustic } \\
\text { omission }\end{array}$ & $\begin{array}{l}\text { Acoustic } \\
\text { reaction } \\
\text { time }\end{array}$ & & & \\
\hline$r$ & $0.314 *$ & 0.284 & $0.368^{*}$ & $0.474 * *$ & $0.375^{*}$ & $0.473 * *$ & & & \\
\hline
\end{tabular}

Note: $* p<0.05, * * p<0.01$.

Abbreviation: VS, vocabulary subtest from Wechsler Adult Intelligence Scale. 
Table 7 Spearman correlational analyses between negative symptoms and scores of neuropsychological measures in relatives of patients with schizophrenia

\begin{tabular}{|l|l|l|l|l|l|l|l|l|}
\hline VS & $\begin{array}{l}\text { Digit } \\
\text { span }\end{array}$ & $\begin{array}{l}\text { Word } \\
\text { span }\end{array}$ & $\begin{array}{l}\text { Spatial } \\
\text { span }\end{array}$ & $\begin{array}{l}\text { Total } \\
\text { cards }\end{array}$ & $\begin{array}{l}\text { Correct } \\
\text { numbers }\end{array}$ & $\begin{array}{l}\text { Perseverative } \\
\text { errors }\end{array}$ & $\begin{array}{l}\text { Random } \\
\text { errors }\end{array}$ & $\begin{array}{l}\text { Correct } \\
\text { categories }\end{array}$ \\
\hline $\mathrm{r}$ & $-0.785^{* *}$ & $-0.540^{* *}$ & $-0.444^{* *}$ & $-0.383^{*}$ & 0.202 & -0.045 & 0.212 & 0.162 \\
\hline $\begin{array}{l}\text { Visual } \\
\text { errors }\end{array}$ & $\begin{array}{l}\text { Visual } \\
\text { omission }\end{array}$ & $\begin{array}{l}\text { Visual } \\
\text { reaction } \\
\text { time }\end{array}$ & $\begin{array}{l}\text { Acoustic } \\
\text { errors }\end{array}$ & $\begin{array}{l}\text { Acoustic } \\
\text { omission }\end{array}$ & $\begin{array}{l}\text { Acoustic } \\
\text { reaction } \\
\text { time }\end{array}$ & -0.043 & \\
\hline$r$ & 0.105 & $0.372^{* *}$ & $0.380^{* *}$ & 0.086 & 0.147 & 0.044 & & \\
\hline
\end{tabular}

Note: $* * P<0.01$.

Abbreviation: VS, vocabulary subtest from Wechsler Adult Intelligence Scale.

as the basic estimation of intelligence; in fact, it reflects the advanced mental capacity and may be a sensitive endophenotype of SP, especially appropriate for the non-psychotic relatives of SP.

$\mathrm{CPT}$ tests the continuous attention and vigilance. Patients with SP showed attention dysfunction in the present study. There is a consistent impaired performance on the "maintenance plus" frontal lobe tasks requiring increased effort and higher central executive processing in neuroleptic-naïve relatives of schizophrenic patients. ${ }^{19}$ Our study showed more visual omission and reaction times only in relatives of patients than in CONP. For the genetic load, relatives from multiplex families had worse performance in most parameters of CPT than relatives from CONP and relatives from simplex families. There was no significant difference between relatives from simplex families and relatives of CONP. Several studies have also reported negative results..$^{20,21}$ Avila et al $^{22}$ found cognitive deficits in only relatives who met criteria for a SP spectrum disorder. Thus, it is possible that the continuous attention deficits are only present in relatives with a particularly high genetic liability.

WCST is a typical cognitive measure of executive function which is associated with prefrontal activity. There is evidence showing that schizophrenic patients and their relatives have more perseverative errors and completed fewer categories in this test. ${ }^{23}$ There are several studies taking genetic load into consideration..$^{24,25}$ Both Aydin et al ${ }^{24}$ and
Schulze-Rauschenbach et $\mathrm{al}^{25}$ found more perseverative errors in WCST in relatives of SP patients than controls; however, there was no significant difference between relatives from multiplex families and simplex families. Similar to the findings of Birkett et al, ${ }^{10}$ some positive results were found among the relatives from multiplex families and simplex families and controls. There was only an increasing trend of perseverative errors in probands and relatives from simplex families and multiplex families. This might be ascribed to the small sample size. A study of Breton et al also indicated a familial resemblance for two tests assessing the executive function of attention, but not for the WCST test in families of patients with SP. ${ }^{26}$ It seemed that the impairment on executive function estimated by WCST was an effective marker, but not a sensitive one.

In this study, patients with SP presented significant negative symptoms. N1-N7 scores in patients from simplex families and multiplex families were similar. This may be partially attributed to some factors, such as course of disease and medications..$^{27,28}$ Interestingly, our results showed that negative symptoms were significantly more severe in relatives from multiplex families than in those from simplex families and controls, which was consistent with the findings of Martín-Reyes et al. ${ }^{29}$ These results support the role of genetic load in the expression of negative symptoms.

The relationship between negative symptoms and cognitive function of SP has been discussed for the view that

Table 8 Stepwise regression analysis of factors associated with negative symptoms in patients with schizophrenia

\begin{tabular}{l|l|l|l|l|l}
\hline Factor & $\boldsymbol{\beta}$ & SE & Beta & t & $P$-value \\
\hline VS & -0.217 & 0.036 & -0.589 & -6.064 & 0.000 \\
WCST correct categories & -12.780 & 4.021 & -1.630 & -3.178 & 0.003 \\
CPT acoustic errors & 0.268 & 0.072 & 0.583 & 3.706 & 0.001 \\
WCST correct numbers & 2.442 & 0.917 & 1.368 & 2.663 & 0.011 \\
CPT visual errors & -0.203 & 0.084 & -0.372 & -2.425 & 0.020 \\
\hline
\end{tabular}

Notes: Standardized regression coefficient: Beta; $R^{2}=0.688, F=5.882, P=0.020$.

Abbreviations: VS, vocabulary subtest from Wechsler Adult Intelligence Scale; WCST, Wisconsin Card Sorting Test; CPT, Continuous Performance Test. 
Table 9 Stepwise regression analysis of factors associated with negative symptoms in relatives of patients with schizophrenia

\begin{tabular}{l|l|l|l|l|l}
\hline Factor & $\boldsymbol{\beta}$ & $\mathbf{S E}$ & Beta & $\mathbf{t}$ & $\boldsymbol{P}$-value \\
\hline VS & -0.152 & 0.015 & -0.739 & -10.203 & 0.000 \\
CPT visual omission & 0.041 & 0.019 & 0.159 & 2.191 & 0.032 \\
\hline
\end{tabular}

Notes: Standardized regression coefficient: Beta; $R^{2}=0.639, F=4.803, P=0.032$.

Abbreviations: VS, vocabulary subtest from Wechsler Adult Intelligence Scale; CPT, Continuous Performance Test.

frontal dysfunction underlies these two symptoms. The systematic review has shown that the negative dimension is significantly and negatively correlated with the majority of cognitive domains, including problem-solving, speed of processing, attention, verbal/visual learning and memory, and IQ. ${ }^{30}$ Similar to these findings, our study also indicated that abstraction, working memory, executive function, and sustained attention were correlated significantly with negative symptoms in patients with SP.

As shown in stepwise regression analysis, VS, correct numbers and categories in WCST, and visual and acoustic errors in CPT in the regression model predicted $68.8 \%$ of the variability in negative symptoms in patients with SP.

The course of disease, medical treatment, other psychiatric symptoms (such as positive symptoms), and disorganized symptoms are involved in various cognitive deficits in patients with SP, and hence, their non-psychiatric relatives may be more appropriate for investigations. Thus, the correlation of these two symptoms was further investigated in the relatives of patients with SP. Our results revealed that the performance of VS, MMAS, and visual omission and reaction times in CPT correlated significantly with negative symptoms. There was still a strong correlation between negative symptoms and cognitive deficits in relatives, although it was weaker than that in patients. VS and visual omission in CPT were included in the final regression model and accounted for $63.9 \%$ of negative symptom variance in stepwise regression analysis.

It has been reported that negative and cognitive symptoms have their own etiology. ${ }^{27}$ Pathological changes in separate brain regions may be the cause of negative symptoms and cognitive symptoms, but the underlying etiologies are related to each other. Longitudinal studies show that negative symptoms and cognitive deficits appear to change at different rates, so there are correlations between them at baseline, but the change in cognition fails to predict the change in negative symptoms at follow-up..$^{27,31}$

Taken together, our results suggest that negative symptoms and cognitive deficits in patients with SP and their relatives were related closely, but they do not completely overlap. The negative symptoms and cognitive deficits may be caused by distributed neuropathology, and the crosssectional correlations between these variables is mediated by the rating methods employed, social cognition, or dysfunctional attitudes. ${ }^{31,32}$

\section{Limitations}

There were several limitations in this study. The sample size was small, and further studies with a large sample size are needed to confirm our findings. The patients received antipsychotics treatment, which may affect the cognitive performances in this study. However, the drug-naïve patients would hardly collaborate with clinicians on these tests. Thus, the unaffected first-degree relatives of patients were included to eliminate the influences of symptoms and medications.

\section{Conclusion}

In conclusion, our study indicates that patients with SP and their relatives show cognitive deficits and a certain degree of negative symptoms. Moreover, relatives from multiplex families exhibit more cognitive deficits and obvious negative symptoms than relatives from simplex families and controls. These two symptoms are genetic characteristics of SP and may worsen as the genetic load increases. The negative symptoms and cognitive deficits in patients and their relatives are related closely, but do not completely overlap. More studies with large sample size are needed to investigate the underlying genetic and neurobiological factors as well as the cognition and psychopathology, which may shed light on the mechanisms underlying SP.

\section{Acknowledgment}

We would like to thank all participants and staff members who assisted with the recruitment at the participating sites.

\section{Disclosure}

The authors report no conflicts of interest in this work.

\section{References}

1. Owen MJ, Sawa A, Mortensen PB. Schizophrenia. Lancet. 2016; 388(10039):86-97.

2. Braff DL, Freedman R. Endophenotypes in studies of the genetics of schizophrenia. In: Davis KL, Charney D, Coyle JT, Nemeroff C, editors. Neuropsychopharmacology: The Fifth Generation of Progress: An Official Publication of the American College of Neuropsychopharmacology. 5th ed. Philadelphia: Lippincott Williams \& Wilkins; 2002:703-716.

3. Şevik AE, Anıl Yağcıoğlu AE, Yağcı̆ğlu S, Karahan S, Gürses N, Y1ldız M. Neuropsychological performance and auditory event related potentials in schizophrenia patients and their siblings: a family study. Schizophr Res. 2011;130(1-3):195-202. 
4. Zilles D, Burke S, Schneider-Axmann T, Falkai P, Gruber O. Diagnosisspecific effect of familial loading on verbal working memory in schizophrenia. Eur Arch Psychiatry Clin Neurosci. 2009;259(6): 309-315.

5. Gooding DC, Matts CW, Rollmann EA. Sustained attention deficits in relation to psychometrically identified schizotypy: evaluating a potential endophenotypic marker. Schizophr Res. 2006;82(1):27-37.

6. Stone WS, Hsi X, Giuliano AJ, et al. Are neurocognitive, clinical and social dysfunctions in schizotaxia reversible pharmacologically? Results from the Changsha study. Asian J Psychiatr. 2012;5(1):73-82.

7. Schizophrenia Working Group of the Psychiatric Genomics Consortium. Biological insights from 108 schizophrenia-associated genetic loci. Nature. 2014;511(7510):421-427.

8. Wu Y, Yao YG, Luo XJ. SZDB: a database for schizophrenia genetic research. Schizophr Bull. 2017;43(2):459-471.

9. Hoff AL, Svetina C, Maurizio AM, Crow TJ, Spokes K, Delisi LE. Familial cognitive deficits in schizophrenia. Am J Med Genet B Neuropsychiatr Genet. 2005;133b(1):43-49.

10. Birkett P, Sigmundsson T, Sharma T, et al. Executive function and genetic predisposition to schizophrenia - the Maudsley family study. Am J Med Genet B Neuropsychiatr Genet. 2008;147(3):285-293.

11. Lam BY, Raine A, Lee TM. The relationship between neurocognition and symptomatology in people with schizophrenia: social cognition as the mediator. BMC Psychiatry. 2014;14:138.

12. Heaton RK. Wisconsin Card Sorting Test Computer Version 4, Research Edition. 4th ed. Lutz, NF: Psychological Assessment Resources; 2003.

13. Luo XR, Li XR. A study on continuous performance task in children with attention deficit hyperactivity disorder. Chin J Clin Psychol. 2002; $10: 6$

14. Cheng Z, Hh L, Zheng H. Reliability and validity of multiple memory assessment scale. Chin Ment Health J. 2004;16:5.

15. Yao S, Chen H, Jiang L, Tam WC. Replication of factor structure of Wechsler Adult Intelligence Scale-III Chinese version in Chinese mainland non-clinical and schizophrenia samples. Psychiatry Clin Neurosci. 2007;61(4):379-384.

16. Kay SR, Fiszbein A, Opler LA. The positive and negative syndrome scale (PANSS) for schizophrenia. Schizophr Bull. 1987;13(2):261-276.

17. Liang S, Deng W, Wang Q, et al. Performance of verbal fluency as an endophenotype in patients with familial versus sporadic schizophrenia and their parents. Sci Rep. 2016;6:32597.

18. Snitz BE, MacDonald AW, Carter CS. Cognitive deficits in unaffected first-degree relatives of schizophrenia patients: a meta-analytic review of putative endophenotypes. Schizophr Bull. 2006;32(1): 179-194.
19. Heydebrand G. Cognitive deficits in the families of patients with schizophrenia. Curr Opin Psychiatry. 2006;19(3):277-281.

20. Cosway R, Byrne M, Clafferty R, et al. Sustained attention in young people at high risk for schizophrenia. Psychol Med. 2002;32(2): 277-286.

21. Egan MF, Goldberg TE, Gscheidle T, Weirich M, Bigelow LB, Weinberger DR. Relative risk of attention deficits in siblings of patients with schizophrenia. Am J Psychiatry. 2000;157(8):1309-1316.

22. Avila MT, Robles O, Hong LE, et al. Deficits on the Continuous Performance Test within the schizophrenia spectrum and the mediating effects of family history of schizophrenia. J Abnorm Psychol. 2006;115(4): 771-778.

23. Godinez DA, Friedman NP, Rhee SH, Miyake A, Hewitt JK. Phenotypic and genetic analyses of the Wisconsin Card Sort. Behav Genet. 2012; 42(2):209-220.

24. Aydın E, Cansu Ülgen M, Tabo A, Devrim Balaban Ö, Yeşilyurt S, Yumrukçal H. Executive function and genetic loading in nonpsychotic relatives of schizophrenia patients. Psychiatry Res. 2017;248: 105-110.

25. Schulze-Rauschenbach S, Lennertz L, Ruhrmann S, et al. Neurocognitive functioning in parents of schizophrenia patients: attentional and executive performance vary with genetic loading. Psychiatry Res. 2015; 230(3):885-891.

26. Breton F, Planté A, Legauffre C, et al. The executive control of attention differentiates patients with schizophrenia, their first-degree relatives and healthy controls. Neuropsychologia. 2011;49(2):203-208.

27. Harvey PD, Koren D, Reichenberg A, Bowie CR. Negative symptoms and cognitive deficits: what is the nature of their relationship? Schizophr Bull. 2006;32(2):250-258.

28. Putnam KM, Harvey PD, Parrella M, et al. Symptom stability in geriatric chronic schizophrenic in patients: a one-year follow-up study. Biol Psychiatry. 1996;39(2):92-99.

29. Martín-Reyes M, Mendoza Quiñones R, Díaz de Villalvilla T, Valdés Sosa M. Perceptual/attentional anomalies in schizophrenia: a family study. Psychiatry Res. 2010;176(2-3):137-142.

30. Dominguez MG, Viechtbauer W, Simons CJ, van Os J, Krabbendam L. Are psychotic psychopathology and neurocognition orthogonal? A systematic review of their associations. Psychol Bull. 2009;135(1): 157-171.

31. Liao JM, Yan H, Liu Q, et al. Relationship between cognitive deficits and negative symptoms in patients with schizophrenia. Chin Gen Prac. 2015;30:3666-3670.

32. Quinlan T, Roesch S, Granholm E. The role of dysfunctional attitudes in models of negative symptoms and functioning in schizophrenia. Schizophr Res. 2014;157(1-3):182-189.
Neuropsychiatric Disease and Treatment

\section{Publish your work in this journal}

Neuropsychiatric Disease and Treatment is an international, peerreviewed journal of clinical therapeutics and pharmacology focusing on concise rapid reporting of clinical or pre-clinical studies on a range of neuropsychiatric and neurological disorders. This journal is indexed on PubMed Central, the 'PsycINFO' database and CAS,
Dovepress

and is the official journal of The International Neuropsychiatric Association (INA). The manuscript management system is completely online and includes a very quick and fair peer-review system, which is all easy to use. Visit http://www.dovepress.com/testimonials.php to read real quotes from published authors. 